\title{
Eating Disorders and Attachment: The Effects of Hidden Family Processes on Eating Disorders ${ }^{\dagger}$
}

\author{
Francoise Ringer ${ }^{1}$ and Patricia McKinsey Crittenden ${ }^{2 *}$ \\ ${ }^{1}$ Private Practice, New Zealand \\ ${ }^{2}$ Family Relations Institute, Miami, FL, USA
}

\begin{abstract}
Aim: This study examined pattern of attachment in cohort of women with an eating disorder to determine what types of selfprotective strategies they used, and further whether there was a specific relationship between strategy and diagnosis.

Method: The participants were 62 young women with an eating disorder (19 with anorexia nervosa, 26 with bulimia nervosa and 17 with bulimic anorexia). Attachment was assessed using the Adult attachment interview (AAI), classified using Crittenden's Dynamic-Maturational Method.

Results: The results indicated that all women with an eating disorder were anxiously attached. About half used an extreme coercive Type $C$ strategy while most of the others combined coercion with an extreme dismissing Type A strategy. The content of the AAIs suggested lack of resolution of trauma or loss among the mothers and also of hidden family conflict between the parents. This in turn elicited extreme strategies for generating parent-child contingency from the daughters.

Conclusions: Central in almost all cases was the women's confusion regarding how parental behaviour was tied causally to their own behaviour. Questions are raised regarding the focus of treatment. Copyright (C) 2006 John Wiley \& Sons, Ltd and Eating Disorders Association.
\end{abstract}

Keywords: eating disorder; attachment; family systems

\section{INTRODUCTION}

Over the last three decades, the incidence of eating disorders among young women has increased dramatically in industrialised countries. Biological,

* Correspondence to: Patricia McKinsey Crittenden, 9481 SW 147 St., Miami, FL 33176, USA. Tel: 1-305-251-1614. Fax: 1-305251-0806.

E-mail: pmcrittenden@att.net

${ }^{\dagger}$ This study is based on the doctoral thesis entitled Early Attachment and Eating Disorders: A Comparative Study between Anorexia Nervosa and Bulimia Nervosa, presented by Francoise Ringer to the Faculty of the School of Psychology, Edith Cowan University, Perth, Australia, 2000. social and personality factors and trauma have been studied extensively as possible causal factors, but the results are far from conclusive. Neither is there consensus regarding treatment. The purpose of this study was to identify the interpersonal strategies of women with eating disorders with the expectation that understanding these would inform prevention and treatment. Because the Dynamic-Maturational Model (DMM) of attachment theory both describes self-protective strategies used by individuals in clinical populations and also offers corresponding assessments, it was used to explore the possible strategic function of disordered eating. Our approach straddles the distinctions among quantitative 
hypothesis testing, qualitative description and theory building. Where possible we state and test hypotheses, but we also go beyond these to consider how the narrative content of the assessment of attachment lays a basis for the attachment strategy and how this might inform treatment.

\section{Attachment and Eating Disorders}

Most studies of attachment use Ainsworth's ABC model (Ainsworth, 1979) or Main's ABCD model (Hesse, 1996; Main \& Solomon, 1986). In these models, Type A refers to dismissing the importance of close relationships and negative feelings about them whereas Type $C$ refers to preoccupation with close relationships and negative feelings about them. Type $B$ refers to a secure valuing of relationships whereas Type $\mathrm{D}$ refers to disorganisation, that is the inability to form a strategy for managing relationships. Previous studies of eating disorders have used only the ABC model, as assessed by several different methods, and had very small samples. The results are contradictory and inconclusive with most, but not all, studies finding (1) few or no secure Type B women with eating disorders and (2) no clarity as to whether most are dismissingly Type A or preoccupyingly Type C (Amstrong \& Roth, 1989; Candelori \& Ciocca, 1998; Cole-Detke \& Kobak, 1996; Fonagy et al., 1996; Heesacker \& Neimeyer, 1990; Kenny \& Hart, 1992; Lavik, Clausen, \& Pedersen, 1991; Ramacciotti et al., 2001; Ward, Ramsay, Turnbull, Benedettini, \& Treasure, 2000). Based on these studies, it seems clear that most women with an eating disorder had problems with childhood family relationships, but the nature of the problem and its relation to eating disorders are unclear.

A study of parental stress in families with a nonorganic failure-to-thrive infant (Crittenden, 1987) and scattered findings in the studies above suggest that mothers of women with eating disorders had unresolved losses to which their daughters responded with compulsive caregiving (Ward et al., 2000). Therefore, we hypothesised that parents' history and hidden problems in the spousal relationship might be crucial to daughters' development of an eating disorder. We used assessment of attachment in an interview about childhood relationships to (1) clarify which self-protective strategies were used by women with an eating disorder and (2) explore the narrative content of their interviews regarding the spousal/parental relationship.

\section{The Dynamic-Maturational Model of Attachment}

The DMM patterns and the eating disorders

In contrast to the three-pattern $\mathrm{ABC}$ and fourpattern $A B C D$ models (see Figure 1), the DMM (Crittenden, 1995, 1997, 2002a) describes a set of complexly organised compulsive and obsessive self-protective strategies that permit differentiation within clinical samples. The strategies constitute complex ways of protecting the self. A total of 10 strategies, plus A/C, are defined (see Figure 2).

Type A strategies involve inhibition of negative effect to prevent attachment figures' anger and are associated with actual threat or danger. The new DMM strategies consist of compulsive caregiving (i.e. A3, role reversal, Bowlby, 1973), compulsive compliance (A4), compulsive promiscuity (A5), compulsive self-reliance (A6, described by Bowlby, 1980), delusional idealisation (i.e. the hostage syndrome, A7) and externally assembled self (A8). Of these patterns, compulsive caregiving (A3) and compliance (A4) best fit the clinical descriptions of some women with restrictive anorexia.

Type C strategies involve exaggerated display of feelings to coerce attachment figures into responding and are associated with uncertain expectation of threat or danger. Individuals using a C3 (aggressive) strategy angrily demand caregivers' compliance. Those using a C5 (punitive) strategy are colder, more distant and self-controlled-as if invulnerable and not needing others. Individuals using these subpatterns mislead others regarding their actual feeling of helplessness and need for comfort. The C4 (feigned helpless) and C6 (seductive, i.e. the appearance of needing rescue from selfinduced risk) strategies exaggerate vulnerability

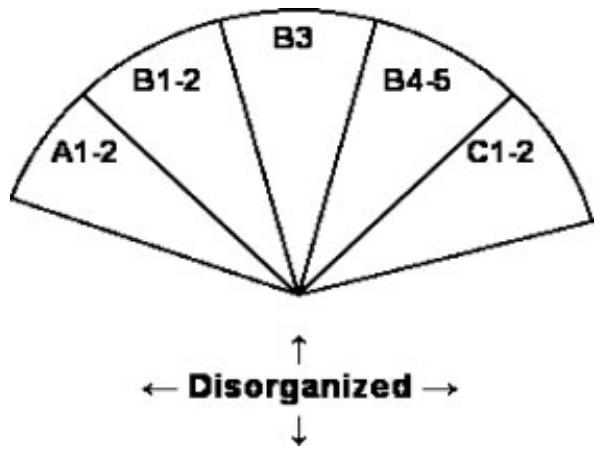

Figure 1. Patterns of attachment identified by Ainsworth and applied by Main to the Adult Attachment Interview 


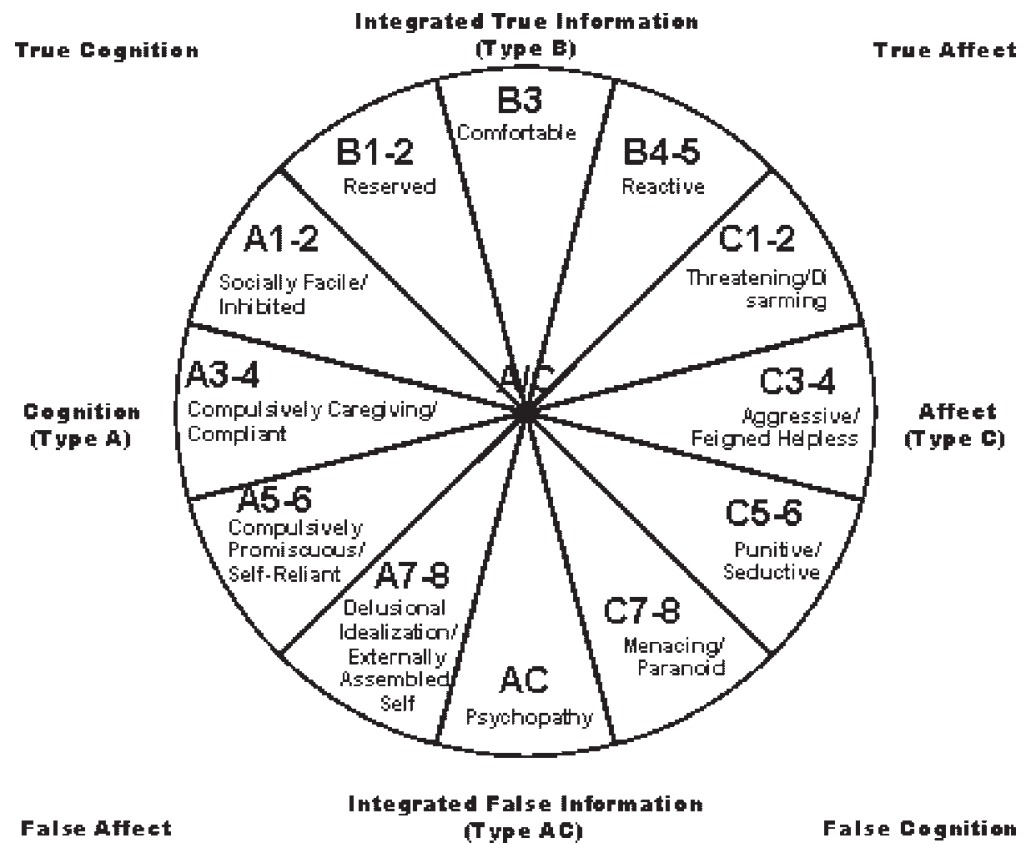

Figure 2. Patterns of attachment identified by Crittenden and applied in the DMM to the Adult Attachment Interview

and hidden anger. Menacing (C7) and paranoid (C8) strategies may develop in cases of exposure to extreme and deceptive danger.

The obsessive strategies augment arousal of others and focus attention on the problem. The problem, however, is made irresolvable by the lack of explicit and accurate communication. The Type $C$ strategy is most likely to organise when children do not know what their parents will do. Sometimes this is because the parents have past traumas or current spousal conflict and prefer to keep their children unaware of it. Because causal relations are not understood, the Type $\mathrm{C}$ strategy may be maintained even when it is ineffective. The C3-4 (aggressive and feigned helpless) and C5-6 (punitive and seductive) strategies fit clinical descriptions of women with eating disorders.

Although A/C combinations have not been assessed in previous studies of eating disorders, it is possible that women with eating disorders will display both strategies. In particular, when there is spousal conflict, false idealisation of one parent might be used to highlight the inadequacies of the other.

The DMM applied to the adult attachment interview

The most common method of assessing attachment in adults is the Adult Attachment Interview
(AAI, George, Kaplan, \& Main, 1986, 1996). The AAI is an hour-long, semi-structured interview about childhood relationships with parents. We applied both the DMM strategies and the DMM method of discourse analysis (Crittenden, 1999, 2000-2004) to the AAI.

The DMM method focuses on the function of discourse. For example, it differentiates dismissing discourse applied to the perspectives and feelings of the self from dismissing discourse applied to those of attachment figures. In the studies cited above, any instance of 'dismissing' was treated as Type A. In the DMM, dismissing the self is indicative of Type A and dismissing others is Type C. A similar distinction was made for preoccupation with self and others. We used the DMM to explore whether applying functional definitions to the classificatory method would clarify the findings on eating disorders. Another study, using the DMM has shown that none of the 20 cases of eating disorder were classified within the ABC patterns, but the sample was too small to find more specific patterning (Zachrisson \& Rindal, in press).

In addition, in the DMM there are several types of lack of resolution of loss or trauma. Those relevant to this study include preoccupied (i.e. an overassociation of the past event with the present circumstances), dismissed (i.e. a lack of appropriate 
association of the event with present circumstances), vicarious (i.e. activation around a trauma or loss that occurred to the attachment figure), imagined (i.e. attribution of a causal relation to an event that is not causally tied to one's present state), anticipated (i.e. an irrational expectation of future trauma or loss) or incompatible (i.e. the event is both dismissed and preoccupying). Lack of resolution does not affect the strategy itself except when events associated with the trauma or loss are experienced-or discussed in an AAI, that is lack of resolution creates temporary breaks in strategic functioning. The literature on eating disorders suggests relatively few serious personal traumas although vicarious or imagined traumas may be experienced.

Finally, there are modifiers that render the strategy non-strategic. These consist of depression, disorientation with regard to source of information and intrusions of forbidden negative affect. Although these modifiers are frequent among psychiatric patients, we did not expect to find them among women with eating disorders.

\section{Hypotheses}

Based on the studies of eating disorders and attachment, DMM theory and our clinical experience, we hypothesised that (1) few, if any, women with an eating disorder would use the normative strategies described by Ainsworth and applied by Main and her colleagues to the AAI. With regard to subgroups within the DMM, (2) we did not expect to find A5-8 (compulsively promiscuous, self-reliant, delusional idealising and externally assembled self) or C7-8 (menacing and paranoid) patterns. On the other hand, we expected to find a substantial number of C3-6 (aggressive \& feigned helpless and punitive \& seductive) strategies, a few A3-4 (compulsive caregiving and compliant) strategies (especially among women with restrictive anorexia) and many A/C combination strategies. We also expected (3) differences among the eating disorders such that women with bulimia would show the least extreme attachment strategies and those with anorexia the most extreme. With regard to modifiers, we expected (4) the strategies of women with eating disorders to be without modifiers. With regard to lack of resolution of trauma or loss, we expected (5) to find little actual danger in the history of women with eating disorders and, where we found lack of resolution of trauma or loss, we expected it to be vicarious, imagined, anticipated or incompatible. Finally, we used cluster analysis to explore (6) whether there were functional groups of women with eating disorders that differed from symptom-based DSM diagnoses.

\section{METHOD}

\section{Sample}

The sample consisted of 62 Anglo-Australian women who were diagnosed with an eating disorder according to DSM-IV criteria. The participants were drawn from hospitals in Perth and Brisbane $(N=40)$, private psychologists and psychiatrists $(N=8)$ and advertising $(N=14)$. The advertisement, approved by the ethics committee, sought participants for research on 'Eating disorders and early attachment to the family of origin'. The advertisement went on to say: 'For this research, I need a sample of 60 women suffering from eating disorders (anorexia and/or bulimia). If you think you have an eating disorder, and you are willing to participate in this project, please contact me and I will explain [... etc.]. Your participation would be to take part in an interview with me, discussing your childhood experience'. There was specifically no mention of family or attachment problems because it was unknown whether there would be such. The 14 respondents to the advertisement who met the DSM-IV criteria for eating disorders were included in the study. Although this is not a pure random sample (as few clinical samples are), we hoped to better reflect the range of eating disorders than by using only a hospital sample, a physician referred sample or a selfreported sample.

\section{Procedure}

Each participant was seen twice. On the first visit, the study was explained and informed consent was obtained. On the second visit, the AAI was administered by the first author.

\section{Assessing Attachment}

The AAI (George, Kaplan, \& Main, 1985) was used to identify the participants' self-protective strategy, that is pattern of attachment. The interview consists of a semi-structured set of questions about individuals' current understanding of their childhood relationships with their attachment figures (usually their parents). Respondents are asked to choose five words or phrases to describe their relationship with 
each parent during childhood and then to provide specific episodes that illustrate each word. Additional questions explore common situations in which protection or comfort might be needed, including instances of distress, illness, hurt and separation. Memories of rejection and threat as well as loss, trauma and abuse are also explored. In closing, respondents are asked why they think their parents behaved as they did and how these early experiences have affected their adult life; these questions assess reflective integration.

Although the DMM classificatory method is based on the original Main and Goldwyn (1984) method, substantial additions have been made. First, the array of outcome possibilities was increased by adding (a) six compulsive, six obsessive and combination $(\mathrm{A} / \mathrm{C})$ strategies, (b) four modifiers and (c) several forms of unresolved trauma and loss. These additions result in greater precision regarding the psychological and interpersonal functioning of individuals, especially in clinical populations. Second, the DMM coding system extends the analysis of the AAI from three to six types of representation, adding procedural and imaged memory and connotative language to the Main and Goldwyn analysis of semantic and episodic memory and integration. Procedural memory in particular adds information on the way in which respondents engage with the interviewer; this has direct implications for therapists' management of treatment.

The AAI requires extensive training for both administration and also classification (which requires passing a standardised reliability test with at least $85 \%$ agreement). Each AAI was transcribed verbatim including silences, stuttering, cries and laughs. The AAIs were coded and classified by two reliable coders; 41 were classified by Crittenden. All classifications were by the 2004 manual (Crittenden, 2000-2004) except lack of resolution of trauma. For this, the criteria were relaxed. Rather than requiring a specific endangering event, cases of repeated threat, such as parental fighting and self-defined threat, such as death of a pet animal, were included. Disagreements were resolved by consensus. The coders were blind to the type of eating disorder of the participants.

\section{Statistical Analysis}

Both major variables (type of eating disorder and pattern of attachment) were categorical. Moreover, the attachment variable, depending upon how it was grouped, had 2-11 categories. This decreased the statistical power of the analyses as the number of categories increased. To increase the power and precision of analysis, we stated precise hypotheses, clustered classifications having the same prediction and used the most precise statistical test possible. All tests were derivatives of the Chi-square. When both variables were ordered, we used Sommer's $d$. When the variables were unordered, but had specific cell-by-cell predictions, we used the deltaprediction statistic (Hildebrand, Laing, \& Rosenthal, 1977). Because low frequency or empty cells do not distort the meaning of the del-PRE, it has the advantage of maximising the power of small samples. We tested the association of attachment subpattern with specific eating disorder (Hypothesis 2) using Goodman and Kruskal's lambda.

\section{RESULTS}

\section{Sample Description}

Among the 62 women, there were 19 cases of restricting type anorexia nervosa, 17 of bingeeating/purging type of anorexia nervosa and 26 of bulimia nervosa. At the time of the research, $50 \%$ of the women with anorexia and 39\% of the women with bulimia were hospitalised. Ninety-one percent $(91 \%)$ of the women with anorexia and $62 \%$ with bulimia received some psychological treatment for their eating disorder.

The participants ranged in age from 18 to 45 years (mean $=24$ years; $\mathrm{SD}=7.1$ ). Their education was high, with two-thirds $(59.7 \%)$ having begun or completed tertiary education. Seventy-four percent (74\%) were single and had never been married or in a long-term (at least 1 year) relationship with a partner, that is most of the participants were by both age and life functions in the transition to adulthood, which is typical of women with eating disorders.

\section{Coder Agreement}

Coder agreement on the data were assessed on 26 AAIs for subclassification (10 categories; $\kappa=0.69$, $p<0.000$ ), depression (3 categories, $\kappa=0.62$, $p<0.000$ ) and lack of resolution (2 categories; $\kappa=0.66, p<0.001)$.

Hypothesis 1: Normative and atypical patterns. All of the 62 women in this sample were classified as insecurely attached: 13\% Type A (dismissing), $50 \%$ Type C (preoccupied) and 37\% combined A/ C. This is consistent with the findings of other studies, but unusual in that we found no Type B 
Table 1. Relations between type of eating disorder and DMM Adult Attachment Interview classifications

\begin{tabular}{lccc}
\hline AAI subclassification & \multicolumn{3}{c}{ Eating disorder } \\
\cline { 2 - 4 } & Anorexia (restricting) & Anorexia/bulimia & Bulimia \\
\hline B & 0 & 0 & 0 \\
A1-2 & $1(5 \%)^{\mathrm{a}}$ & $2(13 \%)$ & 0 \\
A3-4 & $2(10 \%)$ & $2(13 \%)$ & $1(4 \%)$ \\
A5-6 & 0 & 0 & 0 \\
A7-8 & 0 & 0 & 0 \\
C1-2 & 0 & 0 & 0 \\
C3-4 & $3(15 \%)$ & $2(13 \%)$ & $7(27 \%)$ \\
C3-4 (5-6) & $1(5 \%)$ & $1(5 \%)$ & $5(19 \%)$ \\
C5-6 & $3(15 \%)$ & $3(19 \%)$ & $6(23 \%)$ \\
C7-8 & 0 & 0 & 0 \\
A/C3-4 & $4(20 \%)$ & $3(19 \%)$ & $5(19 \%)$ \\
A/C5-6 & $6(30 \%)$ & $3(19 \%)$ & $2(8 \%)$ \\
\hline
\end{tabular}

${ }^{a}$ Entries represent column percentages.

(balanced and secure) eating disordered women whatever. Moreover, only 5\% of the sample fit within the normative Main and Goldwyn patterns (see Table 1).

Hypothesis 2: DMM subpatterns. The sample distribution by subpattern was more informative. The precise findings are shown in Table 2. Over all, in a 36-cell table with an expected cell frequency of 1.7 , there were 16 empty cells and 6 cells that accounted for more than $50 \%$ of the sample, that is the distribution was very skewed in specific ways.

When eating disorder was the dependent variable, the result was significant $(\lambda=0.194, p<0.04)$, indicating that knowing the type of eating disorder predicted the attachment subpattern. We also tested whether the predicted subpatterns were found, using the del-PRE statistic $(\Delta-\simeq=0.27, p=0.018)$. These two tests confirmed hypothesis 2 and indicated that the eating disorders were neither normative, nor spread randomly across the nonnormative categories. Instead they clustered in a small number of predicted groups that differed by eating disorder such that (1) anorexia was associ- ated with Types A3-4 (compulsive caregiving and compliance) and A/C5-6 (idealising of parents and punitive-and-seductive), (2) bulimia with Types C3-4, C3-4(5-6) and A/C3-4 (i.e. aggressive and feigned helpless, sometimes with idealising of parents) and (3) anorexia/bulimia with Types C5-6, A/C3-4 and A/C5-6 (i.e. often punitiveand-seductive, sometimes with idealisation of parents). There was considerable overlap in the classifications (see Table 1).

Hypothesis 3: Extreme strategies and anorexia. The third hypothesis proposed that anorexia would be associated with the most extreme strategies and bulimia with the least. We tested the hypothesis in two ways. First, we estimated extremeness by the value of the subpattern number, that is higher numbers were considered more extreme. We combined $\mathrm{A}, \mathrm{C}$ and $\mathrm{A} / \mathrm{C}$ classifications, based on the subpattern number, for example A3-4 was combined with C3-4 and A5-6 with C5-6, etc. We performed an ANOVA, seeking a linear trend from bulimia to anorexia. Although the means were in the predicted direction, the result was not significant.

Table 2. Distribution of $\mathrm{A}, \mathrm{C}$ and $\mathrm{A} / \mathrm{C}$ strategies by type of eating disorder

\begin{tabular}{lrrr}
\hline Attachment classification & \multicolumn{2}{c}{ Eating disorder } \\
\cline { 2 - 4 } & Anorexia & Anorexia/bulimia & Bulimia \\
\hline Type A1-4 & $4(20 \%)^{\text {a }}$ & $4(25 \%)$ & $0(0 \%)$ \\
Type C3-6 & $6(30 \%)$ & $7(44 \%)$ & $17(65 \%)$ \\
Type A/C3-6 & $10(50 \%)$ & $5(31 \%)$ & $9(35 \%)$ \\
\hline
\end{tabular}

${ }^{\text {a }}$ Entries reflect percent of column, that is type of eating disorder. 
Second, based on DMM theory, we treated Type $\mathrm{A}$ as a response to actual danger and Type $\mathrm{C}$ as the desire to achieve more predictable control over less endangering relationships. Consequently, we treated Type $\mathrm{C}$ as the least extreme strategy, Type $\mathrm{A}$ as more extreme and Type $\mathrm{A} / \mathrm{C}$ as the most extreme. A Chi-square analysis indicated that the distribution was skewed with women with anorexia having more A-based patterns and women with bulimia more C-based patterns $\left(\chi_{(4)}^{2}=12.85, p=0.01\right.$, Table 2). Again, there was considerable overlap among the types of eating disorder.

Hypothesis 4: Modifiers indicative of non-functional strategies: We expected that women with an eating disorder would have functional, albeit ineffective, strategies with a lack of modifiers indicating depression, disorientation or intrusions of negative effect. Six had markers of full or partial depression; this was too few to permit statistical analysis. None had disorientation or intrusions, that is these women were exceptionally strategic.

Hypothesis 5: Unresolved loss and trauma: Onethird of the women had unresolved loss or trauma. Six had the 'preoccupying' form and 13 had DMM forms (2 dismissed, 6 imagined, vicarious or anticipated and 7 dismissed-and-preoccupying). As predicted, anorexia was associated with dismissing forms of lack of resolution, bulimia with preoccupying forms and bulimic anorexia with both preoccupying and dismissing forms $(\Delta-\simeq=0.67, p=0.001)$. To conclude, there were relatively few traumas and losses, but their form was associated with specific eating disorders. In 13 of the 21 cases, there were misattributions of causality or confusion regarding how to manage the event psychologically.

Hypothesis 6: Functional clustering: The 62 cases were entered into a cluster analysis. Three clusters were specified; the test for symmetric, ordinal by ordinal relations between the independent variables (hospitalised, treatment status, strategy, extremeness of strategy and type of lack of resolution of loss or trauma) was significant (Sommer's $d=-0.296, p=0.007)$. Cluster $1(N=8)$ contained all cases of Type A strategies that had no Type C component; one of these cases had preoccupied trauma and two were depressed. Cluster $2(N=19)$ contained the pure Type C strategies of C3-4 and C3-4(5-6); none had depression and 5 had unresolved trauma. Cluster $3(N=35)$ contained the $\mathrm{C} 5-6$ and A/C cases; 15 had lack of resolution of trauma, 1 met the full criteria for the depression modifier and 3 met partial criteria (see Table 3).

\section{DISCUSSION}

\section{Summary of Statistical Findings}

There were several new findings from this study. Most important, we demonstrated that, when a highly differentiated method of coding and classification is used, women with eating disorders are not securely attached. Indeed only a very few, within the range of coding error, fit within the standard Ainsworth or Main and Goldwyn patterns of attachment; instead, using the Main and Goldwyn method, almost all would have been assigned to 'Cannot Classify' (Hypothesis 1).

When the DMM method was applied, several strategies were identified. In almost all the cases, this included an obsessively coercive Type C strategy that was both apparent in the discourse and also enacted with the interviewer; this is consistent with the Ward et al. (2000) finding of a push-pull strategy of both denying any need for help and also seeking care (Hypothesis 2). In almost half of these cases, there was also a Type A idealising component (Hypothesis 2). On the other hand, we did not find any women using the most extreme strategies (A5-8 and C7-8, Hypothesis 2), that is almost all the women in our sample were strategically engaged in a struggle with attachment figures.

In addition, the women in this sample had been exposed to very little danger or death of family members, thus precluding lack of resolution in most cases (Hypothesis 5). Nevertheless, one-third of the women were scored as unresolved when (1) fighting between the parents, (2) vicarious experience of a parent's trauma or (3) an imagined relation between an event and the eating disorder were included as trauma. Most of the unresolved traumas were not based on direct threat to the woman herself. Similarly, very few of these women had any indication of depression (Hypothesis 4). Over all, the sample was (1) non-normative, (2) highly strategic in a coercive way that failed to elicit protection or comfort and (3) lacking in endangering traumas and losses. These women were 
Table 3. Cross-tabulation of type of eating disorder by attachment cluster

\begin{tabular}{lcccr}
\hline Attachment cluster & \multicolumn{3}{c}{ Eating disorder } \\
\cline { 2 - 5 } & Bulimia & Anorexia (restricting) & Anorexia with bulimia & Total \\
\hline 1 & 1 & 3 & 4 & 8 \\
2 & 13 & 13 & 9 & 35 \\
3 & 12 & 4 & 3 & 19 \\
Total & 26 & 20 & 16 & 62 \\
\hline
\end{tabular}

strategically stuck and lacked an adequate explanation for their state.

We also demonstrated that the three types of eating disorder had somewhat different psychological and interpersonal profiles. It should be noted clearly, however, that there was substantial overlap in the classifications, such that knowing the type of eating disorder was not equivalent to knowing the woman's strategy. When we compared clustering based on the psychological aspects of strategy (DMM) with clustering based on eating disorder symptoms (DSM-IV), different groupings were generated (Hypothesis 6). It is not possible to know, from our data, which is the more informative grouping procedure for guiding treatment.

\section{Limitations}

Our research design is very limited. We lack a normative control group and a clinical non-eating disordered comparison group. Both are needed to fully understand these data, especially because a new classificatory method has been used. In addition, this study lacked validating variables. The reason for the omissions is the effort needed to collect, transcribe and classify 62 AAIs. Future studies need to correct these omissions before these findings can be accepted with confidence. On the other hand, 62 AAIs of women with eating disorders offer a much broader understanding than prior studies with small samples and limited potential to discriminate among the eating disorders.

\section{The Content of the AAIs}

In this section, we discuss the experience of women with eating disorders, as seen through the AAI. These both flesh out the data and go beyond it; we hope this will help clinicians to tie the data to clinical experience. Our interest is in the interaction of family and developmental processes that are associated with eating disorders (O'Kearney, 1996).

\section{Discourse and developmental history}

The most outstanding feature of the discourse of women with eating disorders was their reluctance to talk. Many maintained long pauses before answering, answered hesitantly, saying frequently that 'they didn't know why and were sorry but they just couldn't answer the question, they didn't know, they couldn't remember ...'. Frequently, they didn't answer at all, remaining absolutely silent and leaving the interviewer to find a way to move on. Many of the women seemed both self-absorbed and self-concealed. The interpersonal effect was to make the interviewer very uncomfortable and apologetic for asking so many 'difficult' questions. The interviewer struggled to keep the relationship going with these passive, sullenly apologetic, and wordless young women who recalled so little and concluded even less. Put another way, many of the interviews were wordlessly charged with feeling and seemed constantly on the verge of collapse.

The histories that brought the young women to this point were very hard to extract from their AAIs. Indeed, each woman's history was so filled with gaps, cut offs and silences that one could not be confident of its course. But conglomerated and viewed through the discourse, the histories had commonalities. Even so, it was necessary to know directly about the parents to fill the blanks and understand the interpersonal processes of these women.

One must read the parents' AAIs. These were not available for the women in this sample, but other such AAIs have been read by one of us (Crittenden \& Wilkinson, 2005). A generic, agglomerated history can be constructed by knitting together strands from this sample and from cases outside this sample. It contains responsible parents who appeared quite normal and who did not mistreat their daughters. To the contrary, they cared for and tried to meet their daughters' needs - and did not know how they had failed. Their AAIs, however, were organised around their own experiences of trauma and loss-and the mothers' strong desire 
that their daughters should not be affected by this. More than anything, these mothers wanted to protect their daughters from unspeakable threats and disappointments from their own lives. Usually the losses were in the mothers' past, as were some severe dangers (e.g. war, repeated child sexual abuse, loss of a parent), but the threats could also be in present, with the husband.

\section{Triangulation}

The issue, we think, is not the loss or danger itself, but rather how it affected the mothers' behaviour. In their sadness, silence and fear, these mothers both sought a special closeness (that they had lacked with their mothers) with their daughters and also tried to shelter their daughters by walling off their own traumas, both those from their childhood and those in their marriages. Nevertheless, the unresolved traumas or losses affected their behaviour, particularly in inexplicable moments when the mothers retreated or became unavailable just when the daughters thought they had been invited to approach. ${ }^{\mathrm{a}}$

Using the terminology of family systems theory, the problem may be one of structuring an appropriate mother-father-child triad. In families with a child with an eating disorder, we think there are two sorts of distortion of this process. In the more common one, the spousal dyad is so troubled that the child is appropriated as a means of stabilising the marriage. In these cases, marked in our data by a Type C3-6 strategy, the adults abdicate their parental function, at least in crucial moments, and the needs of the spouses determine 'parental' behaviour - and the child feels herself incongruently invisible. In some cases, the young woman idealises one parent as an indirect of highlighting the inadequacies of the other (Type A/C). Perhaps the eating disorder symptom functions to coerce the parent(s) to acknowledge their importance to their daughter-as opposed to her function in their marriage.

The other failure of the parent-child triangle occurs when the spouses form a closed system that barely acknowledges the arrival of the child. In these cases, the child's physical needs are met, but her psychological reality goes unnoticed by parents who are preoccupied with each other. A triangle

\footnotetext{
a This is similar to the process described in detail by Fonagy (1999) in relation to the treatment of a boy with OCD whose parents dissociated in relation to themes connected with loss which reverberated with their losses in the holocaust. The connection could not be clarified from the boy's perspective.
}

never forms and the excluded child adopts a compulsive please-your-attachment-figure strategy that fails. Possibly the symptom of refusal to eat simply announces that, without psychological recognition and emotional inclusion, there is no meaning to life.

\section{Silence and erroneous causal attributions}

In both cases, the girls lacked information about the parents' problems. Consequently, they attributed their mothers' behaviour to themselves. Psychologically, they misunderstood the most basic interpersonal causal relations. Interpersonally, they experienced repeated incongruency when their actions yielded unpleasantly discrepant outcomes. From the girls' perspective, it was as if they did not exist or were not visible as actors in their own relationships. They fought to wrest some recognition from attachment figures who loved them, but whose behaviour was not contingent upon their own. One irony is that telling their mothers how bad they felt was precisely the outcome their mothers wanted to avoid. They had wanted their daughters to be happy-as they had not been. They wanted to be good mothers, as their own mothers had not. Showing them that they had failed to protect their daughters from suffering would create the risk of eliciting terrible anger or, worse, defeat. Not knowing why, the daughters nevertheless knew to be silent, to hold back their words of anguish and blame. In doing this, they protected their mothers, wordlessly, as their mothers had protected them.

In many of the AAIs of women with eating disorders, silence marks the spot where the truth is unspeakable. It is where the young women both demand that their perspective be taken and, concurrently, fail to announce that perspective. It is coercively, obsessively Type C, while still protecting the mother, Type A. The Type A is incomplete because the mother's perspective is not taken (it is not known by the daughter) and the mother is not exonerated (of what could the daughter exonerate her?). Neither does the daughter fulfil the Type $\mathrm{C}$ strategy by completing the revenge. Indeed, should she display anger, her mother would likely see herself as having failed and withdraw further. Children, even adolescent children, cannot fight with their parents if doing so might destroy their parents. What is left is an incomplete coercive strategy, often combined with an incomplete idealising strategy. Unable to discard her loving parents and unable to experience herself as real in their eyes, the daughter finds herself, at the transition to adulthood, running out of options. 
Having unloving parents would free her to derogate and discard them, making a future without the parents possible. Alternatively, resolution of the eating disorder without resolution of the psychological and familial problems might leave her vulnerable to further somatic problems or even personality disorders (Gillberg, Råstam, \& Gillberg, 1995).

Our AAIs suggest the importance of the fathers to the mothers. Many fathers appear to have been hurt in childhood, but to have distanced themselves in ways that troubled their wives. Were their marital relationships function better, both parents might provide more support to their daughters. Nevertheless, the motivation of the fathers to participate in these distorted family processes is at present less clear. Surely they have a story too.

This discussion has been cast around the transition to adulthood (Crittenden, 2002b). Most eating disorders arise in that period, but younger adolescents, older women and some men also have eating disorders. We think our explanation of (1) invisible influences that skew the understanding of causal relations between self and attachment figures and (2) the silence that falsely protects everyone, with (3) somatic symptoms substituting for clear communication has the potential to be applied in these cases as well.

\section{Treatment Implications}

Family level treatment seems essential, but it is complex and has risks. One does not want to pull the woman back into her childhood family, but rather to foster her development towards her own future. Complexity is added when one considers the parents' needs. Balancing the varied needs across the developmental shifts underway (for the daughters, the transition to adulthood; for the parents, the conclusion of their parenting years) is challenging. In this moment, the mothers are losing the hope for resolution of their own pain in their daughter's preparation for a better future whereas the daughters are leaving the not-yet-achieved comfort that they desire. The goals of treatment become creating the possibility of speech about these things (1) without destroying the mother and while (2) enabling the daughter to appreciate what has happened and experience her mother as loving. The goal is not family harmony, but rather sufficient harmony to enable the family to separate and reform as two new and thriving families. The outcome must be that the now-competent daughter leaves home while her now-satisfied mother looks optimistically to both her own and her daughter's future.

How shall this be accomplished? The usual form of family therapy, with everyone together throughout the treatment, seems inappropriate. The daughter needs to move forward without her parents. Moreover, the various individuals have personal issues that require the privacy and intimacy of individual therapy. Each parent may have dyadic issues with the daughter. The couple has marital issues to which the daughter has been both too much and too little privy, that is the subsystems and boundaries have been misaligned and breached; therapy should promote appropriate family organisation. For some therapists, this would indicate having several therapists, each seeing to one subunit. Ironically, this makes the task simpler for the therapists, but reflects the barriers to communication that already exist in the family. It also places on the family members the burden of integrating the disparate therapies. They have already demonstrated their inability to integrate.

An alternate proposal is that a single therapist (or pair of therapists) takes responsibility for dealing with the complexity of the family members' different experiences, psychological processes, personal needs and developmental challenges. This would include varying arrangements of individual, dyadic and family sessions, with everyone knowing what meetings were being held and why it was important for some to occur in privacy. This, of course, would challenge family members' trust, but has the advantage of structuring the therapy itself in a way that modifies the family's boundaries in an appropriate direction.

A particular issue is management of 'forbidden topics'. Young women with an eating disorder have a high rate of death (Löwe et al., 2001; Steinhausen, Seidel, \& Metzke, 2000). Some take their own lives in the months following termination of treatment (Alexander-Mott \& Lumsden, 1994), particularly those with greater psychopathology (Ruuska, Kaltiala-Heino, Rantanen, \& Koivisto, 2005). We think that therapists need to be concerned that exposure of those things that the family has chosen to hide, even to the risk of death, could become dangerous if unveiled too quickly or too completely. For example, one or both parents might become severely depressed or even suicidal if 'truth' became the explicit knowledge by all of their failure as parents or spouses. Likewise, the young woman's anger, once expressed, might become so overwhelming as to destroy the targets of her vengeance or the family itself. Living with such effects of her 
anger might become impossible. Too great a focus on the daughter, too clear an attempt to 'rescue' her from her silence could backfire, painfully and possibly irreversibly. Great care needs to be taken to concurrently give voice to the silences and also shape that voice so that neither the young woman nor her parents is harmed. We suggest an explicit focus on the distinctions among intentions (to be a good parent, spouse, daughter), behaviour (which is often clumsy or misguided) and effects (which are often unwanted and unexpected, Crittenden, 2006).

In particular, we suggest (1) exploring the young women's oversimplification of relationships in the absence of sufficient relevant information, (2) facilitating the women's construction of more complex representations of their experience and relationships, (3) clarifying both causal contingencies and also somatic and emotional feelings and (4) increasing the array of possible strategic responses that each woman has available for resolving problems. Having a therapist who is able to manage both the array of relationships and also conflicting information and perspectives might give family members confidence that it is possible to cope with the complexity of their family. In other words, we suggest reflecting, in the form of therapy, the functional organisation and process of defining boundaries and in the content, the complexity and emergent quality of interpersonal understanding.

\section{Directions for future research}

Future research should (1) correct the limitations of this and other studies (specifically the need for both control groups and also substantial sample sizes), (2) replicate this study to confirm or disconfirm our results and (3) expand these findings. Expansion should be directed to understanding the self-protective strategies and psychological functions of other family members. Siblings, in particular, might be studied to determine what roles they take in the family. Elaborating the distinctions among intentions, implementation and effects for both parents and daughters would be theoretically meaningful and clinically relevant. Because of the complexity of family research, it might be best to coordinate intensive family case studies with controlled group designs.

Treatment is, of course, the central issue and this brings back the central finding of this study. When the DMM of attachment is applied to the AAIs of women with eating disorders, the grouping changes such that women with varied eating disorders are clustered on the basis of similar psychological processes. The central treatment question, therefore, is whether therapists should organise treatment around eating issues or around distorted psychological processes and misguided self-protective strategies.

\section{ACKNOWLEDGEMENTS}

The authors thank Claudio Angelo, Rudi Dallos, Noel Howieson, Kasia Kozlowska, Andrea Landini, Aldo Mattucci and Simon Wilkinson for their contributions to this paper.

\section{REFERENCES}

Ainsworth, M. (1979). Infant-mother attachment. American Psychologist, 34, 932-937.

Alexander-Mott, L., \& Lumsden, D. B. (Eds.). (1994). Understanding eating disorders: Anorexia nervosa, bulimia nervosa, and obesity. Washington: Taylor and Francis.

Amstrong, J. G., \& Roth, D. M. (1989). Attachment and separation difficulties in eating disorders: A preliminary investigation. International Journal of Eating Disorders, 8, 141-155.

Bowlby, J. (1973). Attachment and loss. Vol. III: Separation. New York: Basic Books.

Bowlby, J. (1980). Attachment and loss. Vol. III: Loss. New York: Basic Books.

Candelori, C., \& Ciocca, A. (1998). Attachment and eating disorders. In P. Bria, A. Ciocca, \& S. De Risio (Eds.), Psychotherapeutic issues on eating disorders: Models, methods, and results (pp. 139-153). Roma: Societa Editrice Universo.

Cole-Detke, H., \& Kobak, R. (1996). Attachment processes in eating disorder and depression. Journal of Consulting and Clinical Psychology, 64, 282-290.

Crittenden, P. M. (1987). Non-organic failure-to-thrive: Deprivation or distortion? Infant Mental Health Journal, 8, 56-64.

Crittenden, P. M. (1995). Attachment and psychopathology. In S. Goldberg, R. Muir, \& J. Kerr (Eds.), Attachment theory: Social, developmental, and clinical perspectives (pp. 367-406). London: The Analytic Press.

Crittenden, P. M. (1997). Toward an integrative theory of trauma: A dynamic-maturational approach. In D. Cicchetti, \& S. Toth (Eds.), The Rochester Symposium on Developmental Psychopathology, Vol. 10. Risk, Trauma, and Mental Processes (pp. 34-84). Rochester, NY: University of Rochester Press.

Crittenden, P. M. (1999). Attaccamento in eta adulta: Un approccio dinamico-maturativo all'analisi dell'Adult Attachment Interview (A. Landini, Trans.). Milano: Cortina.

Crittenden, P. M. (2000-2004). Adult attachment interview: coding manual for the dynamic-maturational method: Unpublished manuscript.

Crittenden, P. M. (2002a). Attachment theory, information processing, and psychiatric disorder. World Journal of Psychiatry, 1, 72-75.

Crittenden, P. M. (2002b). Transformaciones en las relaciones de apego en la adolescencia: Adaptación frente 
a necrsidad de psicoterapia. Revista de Psicoterpia, 12, 33-62. (In English on www.patcrittenden.com.)

Crittenden, P. M. (2006). Why do inadequate parents do what they do? In O Mayseless (Ed.), Parenting representations: Theory, research, and clinical implications (pp. 388-433). Cambridge: Cambridge University Press.

Crittenden, P. M., \& Wilkinson, S. R. (2005). Invited Symposium: ED patient: Innocent or complicitous victim? An exploration of self-protective strategies in ED. Eating Disorders Conference, London, UK: April 4.

Fonagy, P. (1999). The transgenerational transmission of holocaust trauma: Lessons learned from the analysis of an adolescent with obsessive-compulsive disorder. Attachment and Human Development, 1, 92-114.

Fonagy, P., Leigh, T., Steele, M., Steele, H., Kennedy, R., \& Mattoon, G. (1996). The relation of attachment status, psychiatric classification, and response to psychotherapy. Journal of Consulting and Clinical Psychology, 64, 22-31.

George, C., Kaplan, N., \& Main, M. (1985/1996). Adult attachment interview: Interview protocol. University of California, Berkeley.

Gillberg, I. C., Råstam, M., \& Gillberg, C. (1995). Anorexia nervosa 6 yrs after onset: part I personality disorders. Comprehensive Psychiatry, 36, 61-69.

Heesacker, R. S., \& Neimeyer, G. J. (1990). Assessing object relations and social cognitive correlates of eating disorder. Journal of Counselling Psychology, 37, 419-426.

Hesse, E. (1996). Discourse, memory, and the adult attachment interview: A note with emphasis on the emerging cannot classify category. Infant Mental Health Journal, $17,4-11$.

Hildebrand, D. K., Laing, L. P., \& Rosenthal, H. R. (1977). Prediction analysis of cross classifications. New York: Wiley.

Kenny, M. E., \& Hart, K. (1992). Relationship between parental attachment and eating disorders in an inpatient and a college sample. Journal of Counselling Psychology, 39, 521-526.

Lavik, N. J., Clausen, S. E., \& Pedersen, W. (1991). Eating behaviour, drug use, psychopathology and parental bonding in adolescents in Norway. Acta Psychiatrica Scandinavica, 84, 387-390.

Löwe, B., Zipfel, S., Buchholz, C., Dupont, Y., Reas, D. L., \& Herzog, W. (2001). Long-term outcome of anorexia nervosa in a prospective 21-year follow-up study. Psychological Medicine, 31, 881-890.

Main, M., \& Goldwyn, R. (1984). Adult attachment scoring and classification systems. Unpublished manuscript, University of California, Berkeley, CA.

Main, M., \& Solomon, J. (1986). Discovery of a new, insecure disorganized/disoriented attachment pattern. In T. B. Brazelton, \& M. Yogman (Eds.), Affective development in infancy (pp. 95-124). Norwood, NJ: Ablex.

O'Kearney, R. (1996). Attachment disruption in anorexia nervosa and bulimia nervosa: A review of theory and empirical research. International Journal of Eating Disorder, 20, 115-127.

Ramacciotti, A., Sorbello, M., Pazzagli, A., Vismara, L., Mancone, A., \& Pallanti, S. (2001). Attachment processes in eating disorders. Eating $\mathcal{E}$ Weight Disorders, 6, 166-170.

Ruuska, J., Kaltiala-Heino, R., Rantanen, P. \& Koivisto, A.-M. (2005). Psychopathological distress predicts suicidal ideation and self-harm in adolescent eating disorder outpatients. European Journal of Child and Adolescent Psychiatry, 14, 276-281.

Steinhausen, H. C., Seidel, R., \& Metzke, C. W. (2000). Evaluation of treatment and intermediate and longterm outcome of adolescent eating disorders. Psychological Medicine, 30, 1089-1098.

Ward, W. A., Ramsay, R., Turnbull, S., Benedettini, M., \& Treasure, J. (2000). Attachment patterns in eating disorders: Past in the present. In International Journal in Eating Disorders, 28, pp. 370-376.

Zachrisson, H. D., \& Rindal, G. (in press). Attachment in Anorexia Nervosa: An exploration of associations with eating disorder psychopathology and psychiatric symptoms. Eating and Weight Disorders. 
Copyright of European Eating Disorders Review is the property of John Wiley \& Sons Limited 1996 and its content may not be copied or emailed to multiple sites or posted to a listserv without the copyright holder's express written permission. However, users may print, download, or email articles for individual use. 